\title{
Neural respiratory drive in obesity
}

\author{
J Steier, ${ }^{1,2}$ C J Jolley, ${ }^{1,2}$ J Seymour, ${ }^{1,2}$ M Roughton, ${ }^{2,3}$ M I Polkey, ${ }^{2}$ J Moxham
}

- Additional data are published online only at http://thorax.bmj. com/content/vol64/issue8

${ }^{1}$ King's College London School of Medicine, London, UK; ${ }^{2}$ Royal Brompton Hospital, London, UK;

${ }^{3}$ University College London,

Cancer Trials Centre, UK

Correspondence to:

Dr J Steier, Chest Unit, King's College London School of

Medicine, Denmark Hill, London SE5 9PJ, UK;

joerg.steier@kcl.ac.uk

Received 16 October 2008 Accepted 5 April 2009

Published Online First

20 April 2009

\section{ABSTRACT}

Background: The load imposed on ventilation by increased body mass contributes to the respiratory symptoms caused by obesity. A study was conducted to quantify ventilatory load and respiratory drive in obesity in both the upright and supine postures.

Methods: Resting breathing when seated and supine was studied in 30 obese subjects (mean (SD) body mass index (BMI) $\left.42.8(8.6) \mathrm{kg} / \mathrm{m}^{2}\right)$ and 30 normal subjects (mean (SD) BMI $23.6(3.7) \mathrm{kg} / \mathrm{m}^{2}$ ), recording the electromyogram of the diaphragm (EMGdi, transoesophageal multipair electrode), gastric and oesophageal pressures.

Results: Ventilatory load and neural drive were higher in the obese group as judged by the EMGdi (21.9 (9.0) vs $8.4(4.0) \% \max , p<0.001)$ and oesophageal pressure swings (9.6 (2.9) vs 5.3 (2.2) $\mathrm{cm} \mathrm{H}_{2} \mathrm{O}, \mathrm{p}<0.001$ ). The supine posture caused an increase in oesophageal pressure swings to $16.0(5.0) \mathrm{cm} \mathrm{H}_{2} \mathrm{O}$ in obese subjects $(p<0.001)$ and to $6.9(2.0) \mathrm{cm} \mathrm{H}_{2} \mathrm{O}$ in non-obese subjects $(p<0.001)$. The EMGdi increased in the obese group to $24.7(8.2) \% \max (p<0.001)$ but remained the same in non-obese subjects (7.0 (3.4)\%max, $p=N S)$. Obese subjects developed intrinsic positive end-expiratory pressure (PEEPi) of 5.3 (3.6) $\mathrm{cm} \mathrm{H}_{2} \mathrm{O}$ when supine. Applying continuous positive airway pressure (CPAP) in a subgroup of obese subjects when supine reduced the EMGdi by $40 \%$, inspiratory pressure swings by $25 \%$ and largely abolished PEEPi (4.1 (2.7) vs $0.8(0.4) \mathrm{cm} \mathrm{H}_{2} \mathrm{O}$, $\mathrm{p}=0.009$ ).

Conclusion: Obese patients have substantially increased neural drive related to BMI and develop PEEPi when supine. CPAP abolishes PEEPi and reduces neural respiratory drive in these patients. These findings highlight the adverse respiratory consequences of obesity and have implications for the clinical management of patients, particularly where the supine posture is required.

Obesity is a rapidly increasing public health problem. ${ }^{12}$ Ventilatory impairment due to increased body mass occurs, causing complications during hospital admissions, contributing to increased morbidity and mortality. ${ }^{3}$ Mechanical indices of ventilatory load have been studied, and increase in the supine posture. ${ }^{4-9}$ There is evidence that obese subjects develop intrinsic positive endexpiratory pressure (PEEPi) when supine and have expiratory flow limitation, ${ }^{5}$ probably due to the low lung volumes at which obese subjects breathe. ${ }^{8}$ However, accurate measurement of inspiratory pressures is difficult because of measurement artefacts of oesophageal and gastric pressure in the supine position. ${ }^{6}{ }^{10}$ Respiratory muscle electromyography (EMG), which provides an index of global respiratory motor drive, can add valuable information to that from mechanical indices. Although not a new concept, hitherto the measurement of respiratory muscle EMG has been limited to documenting relative changes in muscle recruitment with changes in posture or responses to carbon dioxide-stimulated breathing. ${ }^{71-13}$ Absolute levels of neural respiratory drive in response to the load imposed on the respiratory muscles in obesity have not been described. ${ }^{14}$

This study was undertaken to determine the increased respiratory load and neural drive of obese subjects when seated and supine. Besides an increase in body mass, multiple other confounders of metabolic, hormonal, chemoreflex and behavioural origin may contribute to increased motor drive, all of them reflected in an increased central respiratory motor drive, as measured by the diaphragm EMG. For this purpose, we measured neural respiratory drive to the diaphragm and to the extradiaphragmatic respiratory muscles, inspiratory pressures and ventilation. We hypothesised that neural respiratory drive is progressively higher with increasing obesity and that drive further increases when supine.

\section{METHODS}

Obese subjects were recruited from the metabolic outpatient clinic at King's College Hospital and healthy normal subjects followed an announcement of the study on the hospital intranet.

Age, sex, height, weight, body mass index (BMI), waist and hip circumference, waist-to-hip ratio and neck circumference as well as smoking history were recorded. The patients filled in the Medical Research Council (MRC) Dyspnoea Scale, ${ }^{15}$ the Epworth Sleepiness Scale (ESS $)^{16}$ and the Hospital Anxiety and Depression Score (HADS). ${ }^{17}$ All subjects underwent standardised spirometry. ${ }^{18} 19$ Vital capacity was measured in the sitting and supine positions. Arterialised earlobe blood was analysed for blood gases (Bayer Rapidlab 248, Diamond Diagnostics, Massachusetts, USA).

\section{Respiratory pressures and EMG of the diaphragm and extradiaphragmatic respiratory muscles}

Two balloon catheters (Cooper Surgical, Connecticut, USA) for the measurement of oesophageal (Poes) and gastric (Pgas) pressures lubricated with lidocaine $(2 \%)$ gel were introduced via one nostril into the oesophagus (filled with $0.5 \mathrm{ml}$ air) and the stomach (filled with $2 \mathrm{ml}$ air) in the standard manner ${ }^{14}$ and the positioning checked as described by Baydur et al..$^{20}$ In addition, a custommade multipair electrode catheter (Yinghui Medical, Guangzhou, China) was inserted via one nostril to record the transoesophageal EMG of the diaphragm (EMGdi), as previously described. ${ }^{21-24}$ The EMG signals of the neck muscles (sternocleidomastoid), parasternal intercostals and abdominal (external oblique) muscles were recorded using 


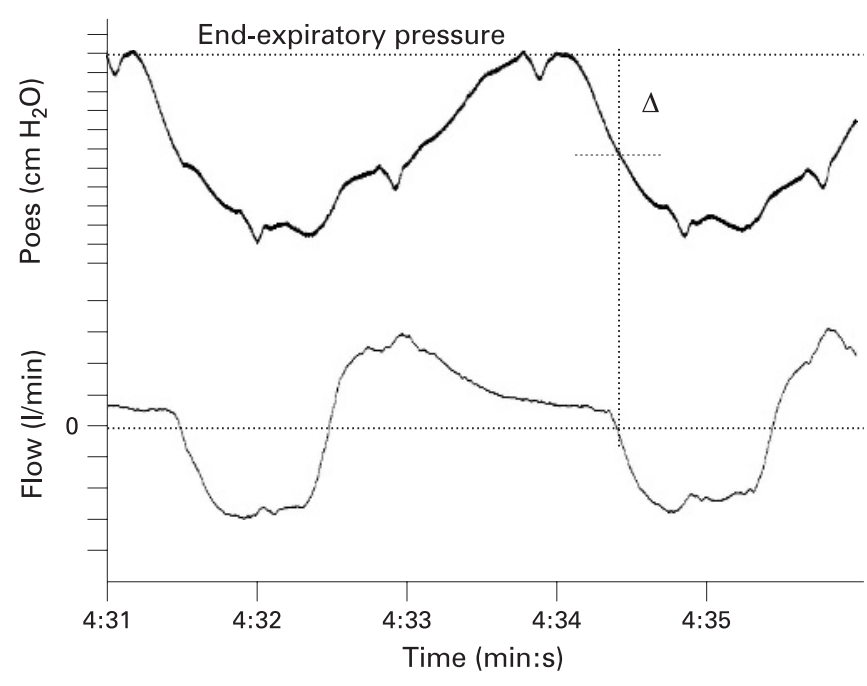

Figure 1 Intrinsic positive end-expiratory pressure (PEEPi) as defined by change of oesophageal pressure ( $\triangle \mathrm{Poes}$ ) from end-expiratory baseline prior to inspiratory flow (vertical dashed line) in the supine posture in a morbidly obese subject.

surface electrodes (Kendall Arbo, Tyco Healthcare, Neustadt, Germany) from standard positions. ${ }^{25-27}$

The following manoeuvres were performed and EMG and pressures recorded: ${ }^{14}$

- Maximum inspiratory pressure (PImax)

- Maximum expiratory pressure (PEmax)

- Sniff pressures (nasal (Pnasal), oesophageal (Poes) and transdiaphragmatic (Pdi))

- Cough gastric pressure (cough Pgas)

- Total lung capacity manoeuvre (TLC)

- "Sprint" (15 s) maximal voluntary ventilation (MVV)

PImax, sniff, TLC and MVV manoeuvres have been shown to produce maximal or near maximal diaphragm activation, and the highest value achieved by these manoeuvres was taken to define maxima for the inspiratory muscles. ${ }^{21}{ }^{24} 28$ PEmax and cough Pgas manoeuvres were chosen to determine the reference for the maximum abdominal muscle EMG.

\section{Recording of spontaneous breathing}

Resting breathing was recorded for 5 min while relaxed, seated in an armchair, and for 5 min lying supine on a bed, the head resting on a pillow, wearing a noseclip, breathing through a flanged mouthpiece connected to a pneumotachograph. Mean (SD) EMG and pressure data for all comparable breaths during this period were analysed. Electromechanical coupling of the diaphragm sitting and supine was described in terms of $\Delta \mathrm{Pdi} /$ EMGdi. ${ }^{14}$ Dynamic compliance was derived from the change in oesophageal pressure and volume during inspiration, ${ }^{14}$ measured for 5-10 comparable breaths. Volume was derived from the flow signal. PEEPi was defined as the change of oesophageal pressure from end-expiratory baseline pressure prior to the beginning of inspiratory flow; $;^{5}$ at least 10 breaths were analysed and the mean reported (fig 1; additional information on PEEPi is described in fig E1 in the online supplement).

In addition, a subgroup of seven obese patients was studied when receiving continuous positive airway pressure (CPAP; Resmed S8 Elite II, San Diego, California, USA) delivered through a full facemask (Respironics Performa Trak, Murrysville, Pennsylvania, USA) and titrated against PEEPi.

\section{Data analysis and statistics}

EMG and pressure data were saved and analysed with Chart Version 5.4 (ADInstruments, Colorado Springs, Colorado, USA) on a Mac Powerbook Pro Computer (Apple Computers, Cupertino, California, USA). The results were further analysed using SPSS Version 16 (SPSS, Chicago, Illinois, USA) for Mac OS X, figures were plotted using SPSS and Microsoft Powerpoint 2004 (Microsoft, Seattle, Washington, USA). Following testing for normality, results are given as mean (SD). A $p$ value of $<0.05$ was considered significant. The correlation between EMGdi and BMI was plotted in a scattergraph and $R^{2}$ reported for seated and supine measurements. A repeated measures one-way ANOVA was performed including post hoc analysis using Bonferroni's correction for multiple comparisons. Questionnaire data were expressed as median (interquartile range). Other parametric data were compared using paired and unpaired $t$ tests, non-parametric data using the Mann-Whitney rank sum test and categorical data using the Fisher exact test. Multiple linear regression analysis was performed to establish independent predictors of PEEPi. The variables age, sex, neck circumference, waist-to-hip ratio and $\mathrm{BMI}$ were entered into a forward model. ${ }^{29}$

\section{RESULTS}

Sixty subjects were measured, 30 obese $\left(B M I \geqslant 30 \mathrm{~kg} / \mathrm{m}^{2}\right)$ and 30 non-obese $\left(\mathrm{BMI}<30 \mathrm{~kg} / \mathrm{m}^{2}\right)$. The obese group had the same height and sex distribution as the non-obese group, but were heavier and slightly older (table 1). Smoking status was similar in both groups.

On the questionnaires, obese subjects scored higher for daytime fatigue, dyspnoea and anxiety and depression (table 1). Both groups had normal inspiratory and expiratory muscle strength; expiratory muscle strength was higher in the obese group. Dynamic compliance was lower in the obese group; both groups had a decrease in dynamic compliance when changing posture from sitting to supine (table 1).

Obese subjects had lower $\mathrm{FEV}_{1}$ and vital capacity (VC), while the $\mathrm{FEV}_{1} / \mathrm{VC}$ ratio and the fall in VC with posture was not significantly different between the groups. Earlobe blood gas results showed slight but statistically significant differences so that arterial oxygen tension $\left(\mathrm{PaO}_{2}\right)$ was lower and arterial carbon dioxide tension $\left(\mathrm{PaCO}_{2}\right)$ and bicarbonate were higher in the obese subjects (table 1).

When seated, both groups had a similar breathing pattern with no differences in respiratory rate, tidal volume or minute ventilation. Obese subjects had larger oesophageal and transdiaphragmatic pressure swings. Correlation between EMGdi and $B M I$ was $R^{2}=0.58$ ( $p<0.001$, fig 2). Average end-expiratory gastric and oesophageal pressures were higher in obese subjects, as was inspiratory EMG activity in all muscles studied (table 2, fig 2).

In the supine position, the diaphragm, neck, parasternal intercostal and abdominal muscles were activated more in the obese subjects (table 2, fig 2). The correlation between EMGdi and BMI increased to $R^{2}=0.696$ ( $p<0.001$, fig 2). Oesophageal and transdiaphragmatic pressure swings increased while gastric pressure swings decreased slightly in both groups. Average endexpiratory baseline pressures (Poes, Pgas) were higher in obese subjects. The breathing pattern was similar in both groups. A PEEPi of 5.3 (3.6) $\mathrm{cm} \mathrm{H}_{2} \mathrm{O}$ developed in the obese subjects in the supine posture (table 2 , fig 3 ).

The change from sitting to supine caused a significant increase in EMGdi, oesophageal and transdiaphragmatic pressure swings, and the development of PEEPi in obese subjects 
Table 1 Demographic characteristics of obese and non-obese subjects

\begin{tabular}{|c|c|c|c|}
\hline & Obese group & Non-obese group & p Value \\
\hline Age (years) & $48.3(11.6)$ & $36.0(19.0)$ & 0.004 \\
\hline Sex (M:F) & $21: 9$ & 20:10 & 0.999 \\
\hline Hip circumference $(\mathrm{cm})$ & $126.7(16.5)$ & $98.7(10.7)$ & $<0.001$ \\
\hline Waist circumference $(\mathrm{cm})$ & $130.5(18.9)$ & $84.2(15.2)$ & $<0.001$ \\
\hline Waist-hip ratio & $1.03(0.10)$ & $0.85(0.10)$ & $<0.001$ \\
\hline Height (m) & $1.70(0.08)$ & $1.71(0.09)$ & 0.697 \\
\hline Weight (kg) & $123.4(25.8)$ & $69.5(15.6)$ & $<0.001$ \\
\hline BMI $\left(\mathrm{kg} / \mathrm{m}^{2}\right)$ & $42.8(8.6)$ & $23.6(3.7)$ & $<0.001$ \\
\hline Neck circumference $(\mathrm{cm})$ & $44.5(4.0)$ & $35.7(4.5)$ & $<0.001$ \\
\hline Smoking status $(\mathrm{S} / \mathrm{E} / \mathrm{N})$ & $3 / 10 / 18$ & $1 / 5 / 24$ & 0.173 \\
\hline Epworth Sleepiness Score* & $8.5(6.0,12.0)$ & $3.0(2.0,5.0)$ & $<0.001$ \\
\hline MRC Dyspnoea Score* & $2.0(1.0,3.0)$ & $1.0(1.0,1.0)$ & $<0.001$ \\
\hline HADS-A* & $4.0(3.0,9.0)$ & $0.0(0.0,2.0)$ & $<0.001$ \\
\hline HADS-D* & $4.0(2.0,7.0)$ & $1.0(0.0,1.0)$ & $<0.001$ \\
\hline PImax $\left(\mathrm{cm} \mathrm{H} \mathrm{H}_{2} \mathrm{O}\right)$ & $92.5(33.9)$ & $92.4(36.3)$ & 0.994 \\
\hline Sniff Pnasal $\left(\mathrm{cm} \mathrm{H}_{2} \mathrm{O}\right)$ & $87.7(25.4)$ & $95.0(32.7)$ & 0.337 \\
\hline Sniff Poes $\left(\mathrm{cm} \mathrm{H}_{2} \mathrm{O}\right)$ & $107.3(22.1)$ & $99.0(28.1)$ & 0.229 \\
\hline Sniff Pdi $\left(\mathrm{cm} \mathrm{H}_{2} \mathrm{O}\right)$ & $133.6(23.7)$ & $125.6(39.1)$ & 0.362 \\
\hline Pemax $\left(\mathrm{cm} \mathrm{H} \mathrm{H}_{2} \mathrm{O}\right)$ & $134.4(33.0)$ & $105.4(34.1)$ & 0.001 \\
\hline Cough Pgas $\left(\mathrm{cm} \mathrm{H}_{2} \mathrm{O}\right)$ & $236.8(55.6)$ & $182.5(60.6)$ & 0.001 \\
\hline Cdyn (sitting, $1 / \mathrm{cm} \mathrm{H}_{2} \mathrm{O}$ ) & $0.117(0.047)$ & $0.182(0.065)$ & $<0.001$ \\
\hline Cdyn (lying, $\mathrm{l} / \mathrm{cm} \mathrm{H}_{2} \mathrm{O}$ ) & $0.087(0.043)$ & $0.134(0.051)$ & 0.001 \\
\hline $\mathrm{FEV}_{1}$ (I) & $2.6(0.9)$ & $3.4(1.0)$ & 0.003 \\
\hline $\mathrm{FEV}_{1}$ (\% predicted) & $80.1(21.9)$ & $94.4(18.6)$ & 0.008 \\
\hline VC sitting (I) & $3.4(1.0)$ & $4.1(1.1)$ & 0.006 \\
\hline VC (\% predicted) & $84.4(18.7)$ & $96.7(17.9)$ & 0.012 \\
\hline VC supine (I) & $3.1(1.1)$ & $3.9(1.1)$ & 0.004 \\
\hline $\mathrm{FEV}_{1} / \mathrm{FVC}(\%)$ & $77.7(12.5)$ & $81.4(10.1)$ & 0.211 \\
\hline $\mathrm{PaO}_{2}(\mathrm{kPa})$ & $10.2(0.8)$ & $11.9(1.4)$ & $<0.001$ \\
\hline $\mathrm{PaCO}_{2}(\mathrm{kPa})$ & $5.3(0.5)$ & $4.9(0.3)$ & 0.001 \\
\hline Bicarbonate $(\mathrm{mmol} / \mathrm{l})$ & $25.3(1.9)$ & $24.2(0.8)$ & 0.006 \\
\hline $\mathrm{pH}$ & $7.42(0.03)$ & $7.42(0.02)$ & 0.407 \\
\hline
\end{tabular}

$\mathrm{BMI}$, body mass index; Cdyn, dynamic compliance; $\mathrm{FEV}_{1}$, forced expiratory volume in $1 \mathrm{~s} ; \mathrm{FVC}$, forced vital capacity; $\mathrm{PaCO}_{2}, \mathrm{PaO}_{2}$, arterial carbon dioxide and oxygen tensions; HADS, Hospital Anxiety and Depression Score (A, anxiety; D, depression); Pdi, transdiagraphmatic pressure; Pemax, PImax, maximum expiratory and inspiratory pressures; Pgas, gastric pressure; Poes, oesophageal pressure; Pnasal, nasal pressure; S/E/N, smoker/ex-smoker/non-smoker; VC, vital capacity.

${ }^{*}$ Non-parametric data are given as median (25th, 75th percentiles using Tukey's Hinges).

(table 2). The shift of end-expiratory oesophageal and gastric baseline pressures related to posture was not significantly different between the two groups. Extradiaphragmatic respiratory muscles were more activated in the obese group, both seated and when supine (additional information on the recruitment of extradiaphragmatic muscles is given in fig E2 in the online supplement). While oesophageal pressure swings became larger when supine, gastric pressure swings decreased with change in posture (table 2, fig 3). Neck circumference correlated with EMGdi\%max when sitting $(r=0.545)$ and when supine $(r=0.660$, both $p<0.01)$, but was not an independent predictor of neural respiratory drive.

The quotient of $\Delta$ Pdi/EMGdi was 0.67 (0.32) $\mathrm{cm} \mathrm{H}_{2} \mathrm{O} /$ $\%$ maxEMGdi for the obese group when seated and 0.81 $(0.35) \mathrm{cm} \mathrm{H} \mathrm{H}_{2} \mathrm{O} / \%$ maxEMGdi when supine $(\mathrm{p}<0.001)$. The non-obese group had a $\triangle$ Pdi/EMGdi quotient of 1.27 (0.61) $\mathrm{cm} \mathrm{H}_{2} \mathrm{O} / \%$ maxEMGdi when seated and 1.73 (0.88) $\mathrm{cm} \mathrm{H}_{2} \mathrm{O} / \%$ maxEMGdi when supine $(p=0.005)$. The difference between the obese and non-obese groups was significant in both the sitting and supine positions (both $\mathrm{p}<0.001)$.

The application of 7.3 (1.8) $\mathrm{cm} \mathrm{H}_{2} \mathrm{O}$ CPAP to a subgroup of seven obese patients (all men, age 51.9 (15.6) years, BMI 37.8 (4.9) $\left.\mathrm{kg} / \mathrm{m}^{2}\right)$ when supine led to a reduction of $40.1 \%(95 \%$ confidence interval (CI) $16.5 \%$ to $63.8 \%$ ) in EMGdi, $26.4 \%(95 \%$
CI $13.0 \%$ to $39.5 \%$ ) in oesophageal pressure swing and $25.3 \%$ (95\% CI $14.3 \%$ to $39.0 \%$ ) in transdiaphragmatic pressure swing. PEEPi in these subjects was reduced from $4.1(2.7) \mathrm{cm} \mathrm{H}_{2} \mathrm{O}$ to $0.8(0.4) \mathrm{cm} \mathrm{H}_{2} \mathrm{O}(\mathrm{p}=0.009)$ with CPAP (fig 3), similar to the level of PEEPi in non-obese subjects (table 2 ).

Regression analysis to establish independent predictors of PEEPi revealed an $R^{2}$ of 0.480 (adjusted $R^{2}=0.471$, standard error of estimate $=2.51$ ); age, sex, neck circumference and waist-to-hip ratio were excluded ( $p=0.443, p=0.858, p=0.641$ and $p=0.327$, respectively). The only significant parameter included in the analysis model was BMI $(p<0.001)$ with an unstandardised coefficient of $\mathrm{B}=0.205, \mathrm{SE}=0.028$ (95\% CI 0.149 to 0.262$)$.

\section{DISCUSSION}

This study is the first to quantify neural respiratory drive in obesity. Obese subjects have markedly increased neural respiratory drive, 2-3 times that of non-obese subjects. The levels of neural drive in the obese subjects were similar to those reported in patients with moderate to severe respiratory disease. ${ }^{21} 24$ Similarly, oesophageal and transdiaphragmatic pressure swings were almost doubled. Increased neural drive is related to BMI and neck circumference. A change of posture from the sitting to the supine position leads to further increases in neural respiratory drive and transdiaphragmatic pressure swings in 

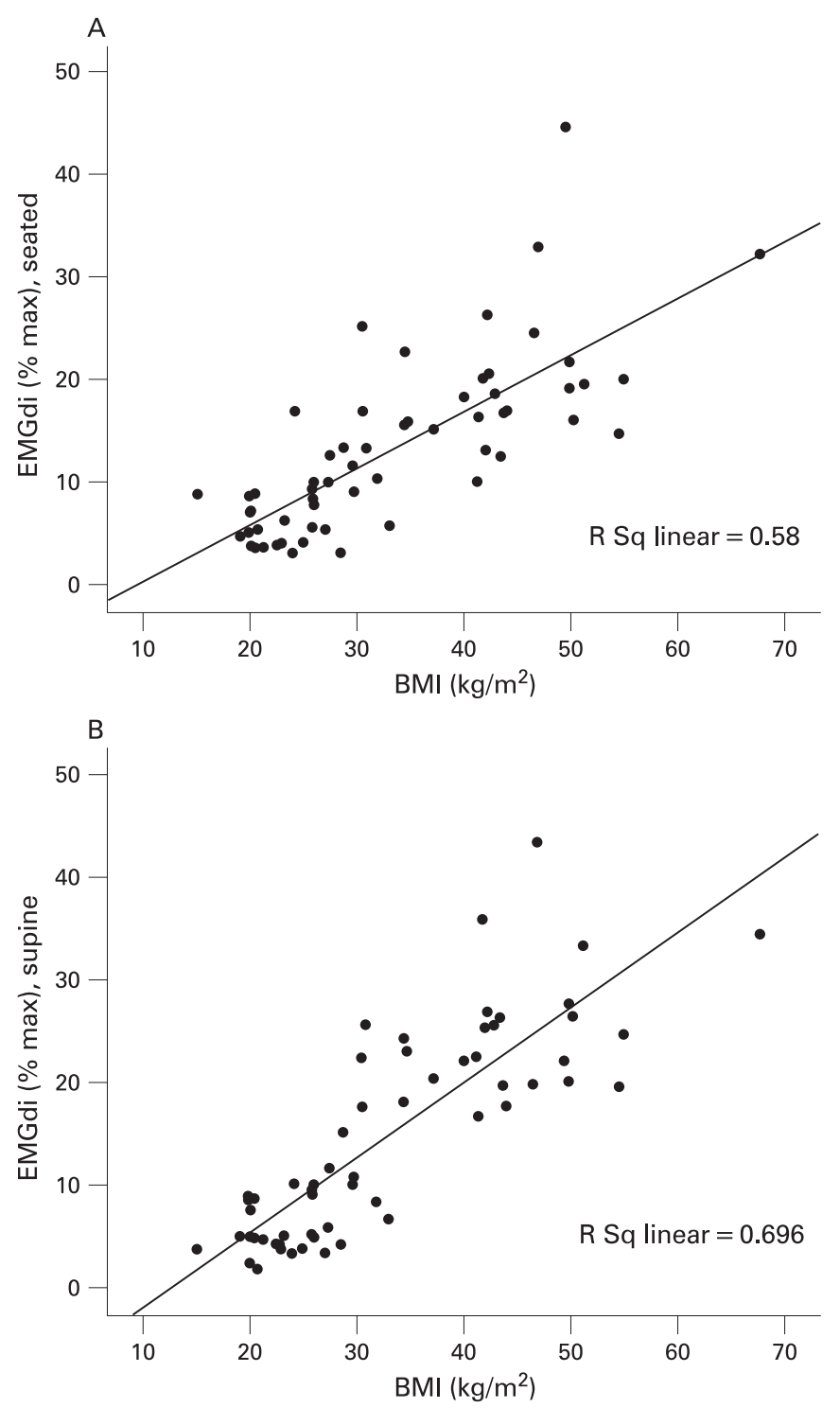

Figure 2 Neural respiratory drive as measured by electromyography of the diaphragm (EMGdi) versus body mass index (BMI) when (A) seated and $(B)$ supine. $A$ high correlation is observed when sitting $\left(R^{2}=0.58\right.$, $p<0.001)$ and supine $\left(R^{2}=0.696, p<0.001\right)$. Interestingly, the slope increases with posture. While the lines for both the seated and supine postures are almost identical in non-obese subjects, neural respiratory drive in obese subjects is increased more in the supine posture (eg, for a subject with a BMl of $50 \mathrm{~kg} / \mathrm{m}^{2}$, neural respiratory drive increases from approximately $20 \%$ to $25 \%$ when supine).

obese subjects. There is reduced efficacy of the diaphragm in obesity, as described by the quotient of transdiaphragmatic pressure per unit of diaphragm activation, which was half that of the non-obese group. Important for the increased work of breathing in obesity is the development of increasing PEEPi, on average $5 \mathrm{~cm} \mathrm{H}_{2} \mathrm{O}$ when supine. The single independent predictor for the development of PEEPi was BMI; on average, PEEPi increased by $0.2 \mathrm{~cm} \mathrm{H}_{2} \mathrm{O}$ per unit of BMI when supine. For the same ventilation, the obese group developed higher neural respiratory drive and larger pressures in the supine position, demonstrating reduced efficiency which confirms the observations of an earlier study. ${ }^{7}$

Interestingly, both groups generated larger oesophageal pressure swings for a given level of drive, contributing to the higher transdiaphragmatic pressure when lying supine, expressed by an increase in the quotient $\Delta$ Pdi/EMGdi. There are several possible explanations for this observation. One is that the contribution of the non-diaphragmatic muscles is proportionately greater. In addition, the diaphragm may generate more tension when supine, acting through the zone of apposition because the contraction is relatively more isometric, although this is not supported by the tidal volume data which showed no significant change with posture. Lastly, because the supine posture induces a fall in lung volume, this results in increased pressure generation because of the lengthtension relationship of the diaphragm. Available data show that functional residual capacity does fall in the supine posture, ${ }^{8}$ 30-32 and this is a plausible explanation. ${ }^{7}$

\section{Clinical significance of findings}

Sinderby and colleagues used a similar electrode for the measurement of EMGdi. ${ }^{21}$ They found values for neural respiratory drive of 8.4 (2.5)\%maxEMGdi in normal subjects, 43.4 (22.1)\% maxEMGdi in patients with severe COPD (mean (SD) $\mathrm{FEV}_{1} 0.69$ (0.19) 1 , mean $\mathrm{FEV}_{1} 28 \%$ predicted) and 45.1 (22.8)\%maxEMGdi in patients with severe restrictive lung disease after prior poliomyelitis infection. Our group found that EMGdi was 27.9 (9.9)\%max in a group of 30 COPD patients (mean (SD) $\mathrm{FEV}_{1} 34.8$ (13.9)\% predicted). ${ }^{24}$ In the 30 non-obese subjects, neural respiratory drive was 8.4 (4.0)\% maxEMGdi when seated and 7.0 (3.4)\%maxEMGdi when supine. The level of neural respiratory drive in obesity (21.9 (9.0)\% maxEMGdi when seated and 24.7 (8.2)\%maxEMGdi when supine) reflects the high load on the ventilatory system and its increase when supine. These observations emphasise the severity of the impact of obesity on the ventilatory system, which is comparable to that in patients with moderately severe lung disease.

The high levels of neural respiratory drive in obesity result in a reduction in ventilatory reserve. Lourenço ${ }^{11}$ investigated hypercapnic and normocapnic obese subjects when seated and measured the increase in EMGdi during carbon dioxide breathing. Interestingly, the hypercapnic patients had a significant lower increase in EMG activity than the normocapnic patients. Lourenço concluded that an inability to increase the activity of the respiratory muscles, reflecting reduced reserve, could play a major role in the genesis of ventilatory failure.

CPAP applied to obese subjects when supine can offset PEEPi. With appropriate CPAP levels, inspiratory flow starts with the onset of the intrathoracic pressure swing. We found that CPAP reduced inspiratory pressure swings by $25 \%$ and neural respiratory drive by $40 \%$. The efficacy of CPAP is likely to be due to its known volume-inflating effect, causing obese subjects to breathe at higher functional residual capacity. The observation that obese subjects recruit inspiratory capacity and dynamically increase end-expiratory lung volume during exercise to optimise pulmonary mechanics, reduce expiratory flow limitation and accommodate increased load without increased breathlessness ${ }^{33}$ supports this hypothesis. In addition, the finding of Pelosi and colleagues ${ }^{4}$ that CPAP is helpful to support ventilation in obese patients during anaesthesia, while normal subjects do not benefit, is consistent with our observations. However, despite offsetting PEEPi with CPAP, obese subjects still had markedly raised levels of EMGdi and oesophageal and transdiaphragmatic pressure swings compared with normal subjects. Besides the increased abdominal load anxiety, an increase in $\mathrm{PaCO}_{2}$ and low maximum oxygen 
Table 2 Electromyography (EMG) and respiratory variables during resting breathing with mouthpiece when seated and supine

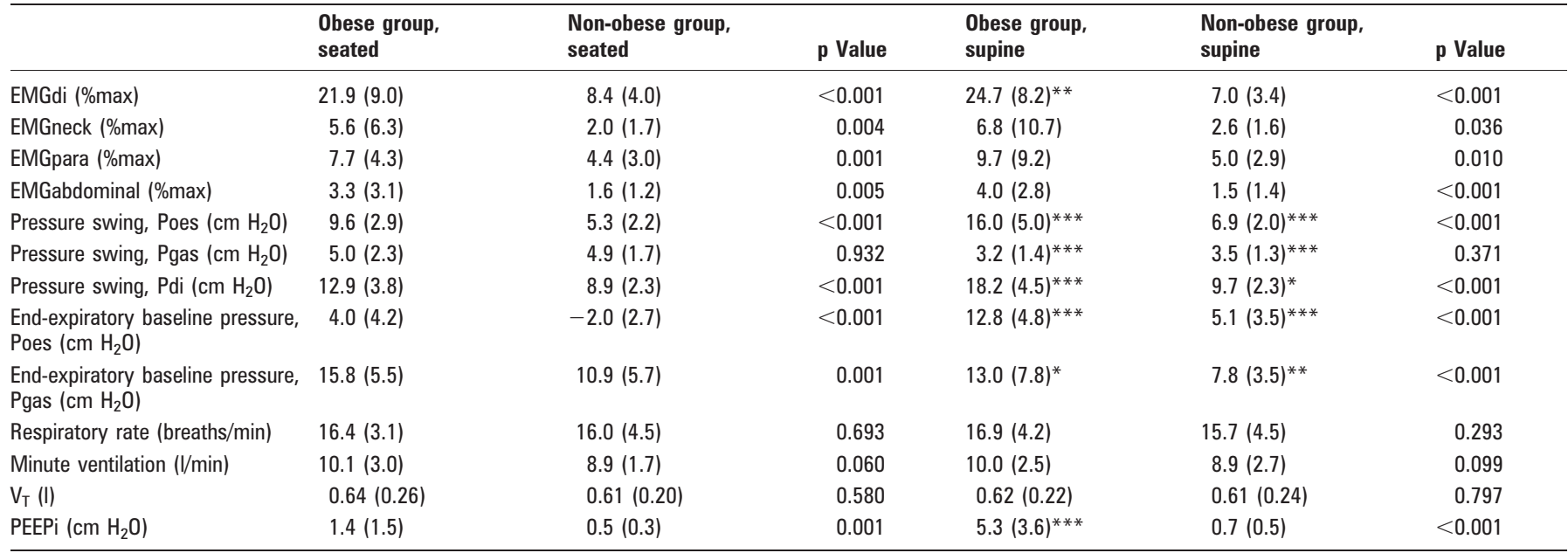

EMGdi, EMG of the diaphragm; EMGneck, EMG of the neck muscles (sternocleidomastoid), EMGpara, EMG of the parasternal intercostals muscles; EMGabdominal, EMG of the abdominal (external oblique) muscles; PEEPi, intrinsic positive end-expiratory pressure; Pdi, transdiaphragmatic pressure; Pgas, gastric pressure; Poes, oesophageal pressure; $\mathrm{V}_{\mathrm{T}}$, tidal volume.

Baseline pressures were measured at end-expiration.

PEEPi was small but slightly higher in the obese group when seated.

Reported $\mathrm{p}$ values refer to comparison of obese vs non-obese group, seated and supine, respectively.

${ }^{*} \mathrm{p}<0.05,{ }^{* *} \mathrm{p}<0.01,{ }^{* *} \mathrm{p}<0.001$ refer to comparisons of parameters seated vs supine.

uptake are factors that may have contributed to increased neural respiratory drive.

Interestingly, Yamane et $a^{34}$ recently reported in 30 Asian patients that the levels of $\mathrm{PaO}_{2}$ and $\mathrm{PaCO}_{2}$ in the inferior pulmonary veins are related to BMI in the supine posture, suggesting that tidal breathing in more obese subjects is close to the "closing volume". ${ }^{035} 36$ They concluded that the inverse relationship between $\mathrm{BMI}$ and $\mathrm{PaO}_{2}$ in the inferior pulmonary

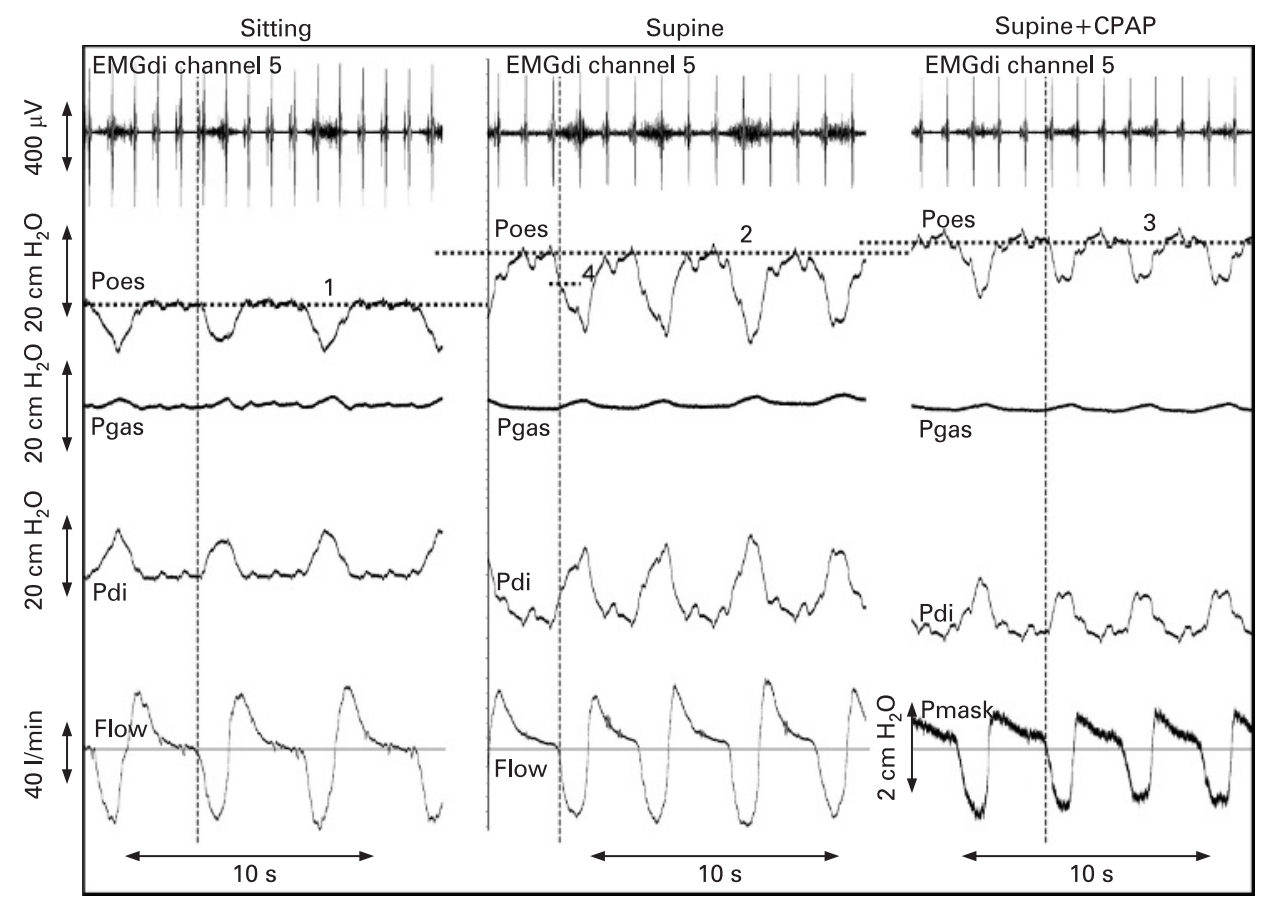

Figure 3 Resting breathing in an obese subject (body mass index $42 \mathrm{~kg} / \mathrm{m}^{2}$, neck circumference $43 \mathrm{~cm}$ ) when seated (left), supine without CPAP (middle) and with CPAP (right). The change in end-expiratory oesophageal baseline pressure is reflected by the horizontal dotted lines (nos 1-3). There is PEEPi of approximately $6 \mathrm{~cm} \mathrm{H}_{2} \mathrm{O}$ (vertical lines indicate the start of inspiratory flow, difference between horizontal dotted lines 2 and $4=\mathrm{PEEPi}$ ). Zero flow is indicated by the horizontal line. The right panel shows the same patient supine breathing with CPAP of $6 \mathrm{~cm} \mathrm{H}_{2} \mathrm{O}$ (full facemask). Neural respiratory drive to the diaphragm increases when changing posture from sitting to supine and decreases with CPAP; PEEPi is offset with CPAP and pressure swings of Poes and Pdi are smaller. Note that on the lower right trace we do not measure flow but mask pressure because flow is predominantly inspiratory when receiving CPAP. The inspiratory deflection in mask pressure was chosen instead of flow to mark the beginning of inspiration (vertical line). CPAP, continuous positive airway pressure; EMGdi, electromyogram of the diagram (channel 5 records the biggest EMG signal, as described in the Methods section); Poes, oesophageal pressure; Pgas, gastric pressure; Pdi, transdiaphragmatic pressure (Pdi = Pgas Poes); PEEPi, intrinsic positive end-expiratory pressure; EMGdi in $\mu \mathrm{V}$, all pressures in $\mathrm{cm} \mathrm{H}_{2} \mathrm{O}$, flow in $\mathrm{l} / \mathrm{min}$. 
veins was a subclinical manifestation of obesity-related respiratory insufficiency. This observation is consistent with our finding that the supine posture imposes an additional load on the ventilatory system in obesity. BMI was the only parameter associated with low $\mathrm{PaO}_{2}$ in the study by Yamane and colleagues, ${ }^{34}$ and it was closely related to PEEPi and increased neural respiratory drive in our study.

\section{Limitations of the study}

There are several factors which make the measurement of true intrathoracic pressure with an oesophageal balloon difficult, and there is a well recognised artefact in the supine posture. Inspiratory flow can only start when intrathoracic pressures are subatmospheric, but measuring the oesophageal pressure at the onset of flow shows it to be positive when supine. The increase in end-expiratory oesophageal baseline pressures when supine was about $7-9 \mathrm{~cm} \mathrm{H}_{2} \mathrm{O}$ in our study, similar to the results of earlier studies. ${ }^{67}$ Importantly, this artefact was the same in the obese and non-obese groups. The shift in baseline pressures is partly due to a displacement on the pressure-volume curve and, in part, it is likely that the mediastinum compresses the oesophageal balloons in the supine posture. ${ }^{637-39}$ Interestingly, the difference in end-expiratory gastric pressure between the obese and non-obese groups (around $5.0 \mathrm{~cm} \mathrm{H}_{2} \mathrm{O}$ ) was similar to the results of Sampson and Grassino. ${ }^{12}$ The finding that changes in the end-expiratory pressure were the same in both groups while EMGdi and oesophageal pressure swing increased much more in the obese subjects make it highly likely that these observations are documenting a true increase in the ventilatory load. However, lung volume may directly affect efficiency, as measured by the quotient of $\Delta \mathrm{Pdi} / \mathrm{EMGdi}$, and it is possible that the differences between obese and non-obese subjects could be smaller than observed if corrected for lung volumes.

The obese group in this study was matched to the non-obese group for sex, height and smoking status. However, the obese subjects were slightly older than the non-obese subjects, which could potentially contribute to differences in neural respiratory drive. The physiological impact of ageing-including stiffening of the rib cage and development of mild emphysema-may cause a slightly higher respiratory drive. ${ }^{40}$ Lung compliance worsens with age and, because they were somewhat older, would be expected to be slightly reduced in the obese group. However, as described by Jolley et al, ${ }^{24}$ neural respiratory drive in normal subjects increases only slightly with age-on average to 11.3 (3.4)\% maxEMGdi in those aged $>50$ years - and therefore a small difference in age (12 years) as reported in our study would have little effect.

\section{CONCLUSION}

Obese subjects have increased neural respiratory drive which is 2-3 times that of non-obese subjects and comparable to that of patients with moderately severe lung disease. The increased neural respiratory drive is strongly related to BMI. Neural respiratory drive in obese subjects increases when changing from the sitting to supine position, while in normal subjects the same level of drive is sustained. In obese subjects PEEPi develops when supine, and this can be offset with CPAP which substantially reduces respiratory drive. CPAP therapy may therefore have a role in the clinical management of severely obese patients when supine. Obesity causes breathlessness and eventually ventilatory failure. Future studies could address the interaction of levels of neural respiratory drive, breathlessness and ventilatory failure, as well as the impact of weight loss.

Acknowledgements: The authors thank Professor Neil Pride for his help with the manuscript and Dr Gerrard Rafferty for his statistical advice.

Funding: JS is the recipient of a long-term Research Fellowship of the European Respiratory Society (No 18).

Competing interests: Professor Yuanming Luo, a close collaborator from the State Key National Laboratory of Respiratory Disease, Guangzhou Medical College, China, has developed the multipair catheter used for the measurement of the diaphragm electromyogram. No patent is pending.

Ethics approval: The study was approved by the King's College Hospital local research ethics committee and informed consent was obtained from each patient.

\section{REFERENCES}

1. See CO, Mensah E, Olopade CO. Obesity, ethnicity, and sleep-disordered breathing: medical and health policy implications. Clin Chest Med 2006:27:521-33.

2. Bray GA. The missing link - lose weight, live longer. N Engl J Med 2007;357:818-20.

3. Nowbar S, Burkart KM, Gonzalez R, et al. Obesity-associated hypoventilation in hospitalized patients: prevalence, effects, and outcome. Am J Med 2004;116:1-7.

4. Pelosi P, Ravagnan I, Giurati G, et al. Positive end-expiratory pressure improves respiratory function in obese but not in normal subjects during anesthesia and paralysis. Anesthesiology 1999;91:1221-31.

5. Pankow W, Podszus T, Gutheil T, et al. Expiratory flow limitation and intrinsic positive end-expiratory pressure in obesity. J Appl Physiol 1998;85:8.

6. Washko GR, O'Donnell CR, Loring SH. Volume-related and volume-independent effects of posture on esophageal and transpulmonary pressures in healthy subjects. J Appl Physiol 2006;100:753-8.

7. Sharp JT, Druz WS, Kondragunta VR. Diaphragmatic responses to body position changes in obese patients with obstructive sleep apnea. Am Rev Respir Dis 1986;133:32-7.

8. Yap JCH, Watson RA, Gilbey $\mathrm{S}$, et al. Effects of posture on respiratory mechanics in obesity. J Appl Physiol 1995;79:7.

9. Milic-Emili J, Mead J, Turner JM. Topography of esophageal pressure as a function of posture in man. J Appl Physiol 1964;19:212-6.

10. Milic-Emili J, Mead J, Turner JM, et al. Improved technique for estimating pleural pressure from esophageal balloons. J Appl Physiol 1964;19:207-11.

11. Lourenco RV. Diaphragm activity in obesity. J Clin Invest 1969;48:1609-14.

12. Sampson MG, Grassino AE. Load compensation in obese patients during quiet tidal breathing. J Appl Physiol 1983;55:1269-76.

13. Sampson MG, Grassino K. Neuromechanical properties in obese patients during carbon dioxide rebreathing. Am J Med 1983;75:81-90.

14. ATS/ERS. ATS/ERS joint statement on respiratory muscle testing. Am J Respir Crit Care Med 2002;166:518-624.

15. Bestall JC, Paul EA, Garrod R, et al. Usefulness of the Medical Research Council (MRC) dyspnoea scale as a measure of disability in patients with chronic obstructive pulmonary disease. Thorax 1999;54:581-6.

16. Johns MW. A new method for measuring daytime sleepiness: the Epworth sleepiness scale. Sleep 1991:14:540-5.

17. Zigmond AS, Snaith RP. The hospital anxiety and depression scale. Acta Psychiatr Scand 1983:67:361-70.

18. British Thoracic Society. Guidelines for the measurement of respiratory function Respir Med 1994;88:165-94.

19. Miller MR, Hankinson J, Brusasco V, et al, for the ATS/ERS Task Force. Standardisation of lung function testing. Standardisation of spirometry. Eur Respir $J$ 2005;26:319-38.

20. Baydur A, Behrakis PK, Zin WA, et al. A simple method for assessing the validity of the oesophageal balloon technique. Am Rev Respir Dis 1982;126:788-91.

21. Sinderby C, Beck J, Spahija J, et al. Voluntary activation of the human diaphragm in health and disease. J Appl Physiol 1998;85:2146-58.

22. Polkey MI, Duguet A, Luo $\mathrm{Y}$, et al. Anterior magnetic phrenic nerve stimulation: laboratory and clinical evaluation. Intensive Care Med 2000;26:1065-75.

23. Luo YM, Harris ML, Lyall RA, et al. Assessment of diaphragm paralysis with oesophageal electromyography and unilateral magnetic phrenic nerve stimulation. Eur Respir J 2000;15:596-9.

24. Jolley CJ, Luo YM, Steier J, et al. Neural respiratory drive in healthy subjects and COPD. Eur Respir J 2009;33:289-97.

25. Maarsingh EJW, van Eykern LA, Sprikkelman AB, et al. Respiratory muscle activity measured with a noninvasive EMG technique: technical aspects and reproducibility. J Appl Physiol 2000;88:1955-61.

26. Duivermann ML, van Eykern LA, Vennik PW, et al. Reproducibility and responsiveness of a noninvasive EMG technique of the respiratory muscles in COPD patients and in healthy subjects. J Appl Physiol 2004;96:1723-9.

27. Lasserson D, Mills K, Arunachalam R, et al. Differences in motor activation of voluntary and reflex cough in humans. Thorax 2006;61:699-705.

28. Luo YM, Moxham J. Measurement of neural respiratory drive in patients with COPD. Respir Physiol Neurobiol 2005;146:165-74.

29. Petrie A, Sabin C. Medical statistics at a glance. 2nd ed. Oxford: Blackwell Publishing, 2005. 
30. Luce JM. Respiratory complications of obesity. Chest 1980;78:626-31.

31. Craig DB, Wahba WM, Don HF, et al. "Closing volume" and its relationship to gas exchange in seated and supine positions. J Appl Physiol 1971;31:717-21.

32. Holley HS, Milic-Emili J, Becklake MR, et al. Regional distribution of pulmonary ventilation and perfusion in obesity. J Clin Invest 1967;46:475-81.

33. Ofir D, Laveneziana P, Webb KA, et al. Ventilatory and perceptual responses to cycle exercise in obese women. J Appl Physiol 2007; 102:2217-26.

34. Yamane T, Date T, Tokuda M, et al. Hypoxemia in inferior pulmonary venis in supine position is dependent on obesity. Am J Respir Crit Care Med 2008;178:295-9.

35. Leblanc $\mathbf{P}$, Ruff F, Milic-Emili J. Effects of age and body position on "airway closure" in man. J Appl Physiol 1970;28:448-51.
36. Farebrother MJB, McHardy GJR, Munro JF. Relationship between pulmonary gas exchange and closing volume before and after substantial weight loss in obese subjects. BMJ 1974;3:391-3.

37. Mead J, Gaensler EA. Esophageal and pleural pressures in man, upright and supine. J Appl Physiol 1959;14:81-3.

38. Ferris BG, Mead J, Frank NR. Effect of body position on esophageal pressure and measurement of pulmonary compliance. J App/ Physiol 1959;14:521-4.

39. Knowles JH, Hong SK, Rahn H. Possible errors using esophageal balloon in determination of pressure-volume characteristics of the lung and thoracic cage. J App/ Physiol 1959;14:525-30.

40. Estenne M, Yernault J-C, De Troyer A. Rib cage and diaphragm-abdomen compliance in humans: effects of age and posture. J Appl Physiol 1985;59:1842-8.

\section{Lung alert}

\section{Potential treatment for XDR-TB?}

Extensively drug-resistant tuberculosis (XDR-TB) is associated with alarmingly high rates of mortality and is thought to account for an increasing proportion of cases of the infection worldwide. Multidrug-resistant tuberculosis (MDR-TB) describes strains of tuberculosis that are resistant to at least two main first-line drugs. XDR-TB is MDR-TB that is also resistant to three or more second-line drugs. Some experts have speculated that XDR-TB is effectively untreatable.

Traditionally, $\beta$-lactam antibiotics have never proved to be a useful treatment in tuberculosis as Mycobacterium tuberculosis produces a highly active $\beta$-lactamase. This laboratory-based study examined the effects of combining various $\beta$-lactams with clavulanate, a $\beta$-lactamase inhibitor found to be effective against the $\beta$-lactamase produced by $M$ tuberculosis. The researchers found that the combination of meropenem and clavulanate had potent activity against drug-susceptible laboratory strains of $M$ tuberculosis. Furthermore, they discovered that the meropenemclavulanate combination inhibited the growth of 13 strains of XDR-TB. The combination was found to be equally effective against both susceptible and XDR strains.

The synergistic combination of these two commonly used drugs could be used as a potential treatment in XDR-TB, considered by many to be incurable. A clinical trial would seem to be appropriate.

- Hugonnet JE, Tremblay LW, Boshoff HI, et al. Meropenem-clavulanate is effective against extensively drug-resistant Mycobacterium tuberculosis. Science 2009;323:1215-8.

\section{G Tack}

Correspondence to: Dr G Tack, Specialist Registrar, University Hospital Aintree, Liverpool, UK; g.tack@nhs.net 